\title{
The Antioxidative, Antiaging, and Hepatoprotective Effects of Alkali-Extractable Polysaccharides by Agaricus bisporus
}

\author{
Shangshang Li, ${ }^{1,2}$ Juan Li, ${ }^{3}$ Jianjun Zhang, ${ }^{2}$ Wenshuai Wang, Xiuxiu Wang, \\ Huijuan Jing, ${ }^{2}$ Zhenzhen Ren, ${ }^{2}$ Zheng Gao, ${ }^{2}$ Xinling Song, ${ }^{2}$ Zhiyuan Gong, ${ }^{1}$ and Le Jia ${ }^{2}$ \\ ${ }^{1}$ Institute of Agricultural Resources and Environment, Shandong Academy of Agricultural Sciences, Key Laboratory of Wastes \\ Matrix Utilization, Ministry of Agriculture, Jinan 250100, China \\ ${ }^{2}$ College of Life Science, Shandong Agricultural University, Taian 271018, China \\ ${ }^{3}$ Key Laboratory of Plant Nutrition and Fertilizer, Ministry of Agriculture/Institute of Agricultural Resources and Regional Planning, \\ Chinese Academy of Agricultural Sciences, Beijing 100081, China
}

Correspondence should be addressed to Zhiyuan Gong; sdgzy2656@126.com and Le Jia; jiale0525@163.com

Shangshang Li, Juan Li, Jianjun Zhang, and Wenshuai Wang contributed equally to this work.

Received 17 March 2017; Revised 22 June 2017; Accepted 6 July 2017; Published 22 August 2017

Academic Editor: Kuttulebbai N. S. Sirajudeen

Copyright (C) 2017 Shangshang Li et al. This is an open access article distributed under the Creative Commons Attribution License, which permits unrestricted use, distribution, and reproduction in any medium, provided the original work is properly cited.

The aim of this work was designed to investigate the antioxidant, antiaging, and hepatoprotective effects of alkali-extractable polysaccharides (AlAPS) and their three purified fractions (AlAPS-1, AlAPS-2, and AlAPS-3) from Agaricus bisporus in D-galactose induced aging mice. For in vitro antioxidant analysis, both AlAPS and its fractions exhibited moderate reducing power, $\mathrm{Fe}^{2+}$ chelating activities, and potent scavenging activities on hydroxyl and 1,1-diphenyl-2-picrylhydrazyl (DPPH) radicals. The in vivo results demonstrated that the polysaccharides, especially AlAPS-2, showed potential antiaging and hepatoprotective effects by enhancing the antioxidant status, decreasing serum hepatic enzyme activities, and improving the lipid metabolism. This study suggested that the polysaccharides extracted and purified from A. bisporus could be exploited as a potent dietary supplement to attenuate aging and prevent age-related diseases.

\section{Introduction}

It has been reported that the aging, as an inevitable and physiological process in living organism which can induce the gradual loss of body function and increase the probability of age-related diseases including diabetes, cognitive dysfunctions, cancer, stroke, liver failure, atherosclerosis, and Parkinson's diseases, has become a considerable challenge for health problems and disability in later life [1-5]. Recently, more and more scientists have devoted themselves on finding the mechanism; however, no accurate results are obtained. The most acceptant pathogenesis for explaining the aging process is the free radical theory initially proposed by Harman [6]. Previous literatures have demonstrated that the oxidative stress, induced by overplus of reaction oxygen species (ROS), can attack the cell membrane, nucleic acid, protein, enzymes, and other biomacromolecules by peroxidation, leading to many severe cellular and tissular damage contributing to the dysregulation of redox-sensitive signaling pathways and accelerating the progress of aging [7]. Naturally, the cells and organisms possess antioxidant enzyme systems including superoxide dismutase (SOD), catalase (CAT), and glutathione peroxidase (GSH-Px) on controlling the propagation of free radicals, limiting the formation of new free radicals, and removing the excess ROS in cells [8]. In order to reduce the oxidative damage of free radicals, a lot of synthetic antioxidants, such as butylated hydroxytoluene (BHT) and butyl hydroxy anisd (BHA), are widely used clinically and daily on preventing the formation of ROS and delaying the aging progress [9]. Nevertheless, studies have indicated that synthetic antioxidants have potential side-effects including liver damage and carcinogenesis in the long-time use [10]. 
Urgently, it seems necessary on exploiting natural and safe antioxidants and investigating the antioxidant and antiaging effects against aging progress.

Mushrooms, commonly used as traditional, pharmaceutical, and edible drugs/nutraceutical, have been attracting increasing attentions and become a very active domain of research in recent years owing to the physiological benefit to humans [11]. Besides, the mushrooms contain various excellent antioxidants including polyphenolic compounds, flavonoids, vitamins, polysaccharides, and carotenoids, which could prevent the ROS-induced damage and reduce the risk of chronic diseases [12]. As the most substance in the mushrooms, the polysaccharides have been isolated and confirmed to have potentially biological properties containing antioxidant, antitumor, antibacterial, immunomodulatory, antiaging, anti-inflammatory, and hepatoprotective activities [13-15], manifesting that polysaccharides have tremendous potentials for promoting human health [16].

Many literatures have demonstrated that the Agaricus bisporus, one of the most economically important edible mushrooms which were commonly known as the white button mushroom (WBM), has many biological activities of antitumor, antiaromatase, antimicrobial, and antioxidant activities due to the abundant nutritional components of proteins, polysaccharides, vitamins, nucleotides, and unsaturated fatty acids [17]. It is also reported that the biological activities are mainly attributed to polysaccharides [18]. However, no report about the aging effects of alkali-extractable polysaccharides (AlAPS) by A. bisporus against D-galactose induced aging mice has been published up till now.

In present study, the in vivo antioxidant activities and in vitro antiaging effects of AlAPS and its major fractions (AlAPS-1, AlAPS-2, and AlAPS-3) were investigated, aiming to establish the possible antiaging mechanism in the Dgalactose induced aging mice. Furthermore, the molecular weight and monosaccharide compositions were also analyzed.

\section{Materials and Methods}

2.1. Chemicals. The fruiting body of A. bisporus was purchased from local commercial markets (Taian, China). DEAE-52 cellulose and 1,1-diphenyl-2-picrylhydrazyl (DP$\mathrm{PH}$ ) were purchased from Sigma Chemicals Company (St. Louis, USA). The diagnostic kits for assaying activities of superoxide dismutase (SOD), glutathione peroxidase (GSH$\mathrm{Px})$, catalase (CAT), and total antioxidant activity (T-AOC), as well as contents of malondialdehyde (MDA) and lipid peroxidation (LPO), were purchased from Jiancheng Biotechnology Company (Nanjing, China). All the other chemicals and reagents were analytical grade and purchased from local chemical suppliers in China.

2.2. Preparation of AlAPS. The AlAPS from A. bisporus were performed according to a reported method with slight modifications [19]. The dried $A$. bisporus powder was extracted with proper volumes of sodium hydroxide $(1 \mathrm{~mol} / \mathrm{L})$ for $6 \mathrm{~h}$ at $50^{\circ} \mathrm{C}(1: 5, \mathrm{w} / \mathrm{v})$ in a thermostatic water bath. The supernatant homogenate was precipitated with five volumes of ethanol $(95 \%, \mathrm{v} / \mathrm{v})$ overnight $\left(4^{\circ} \mathrm{C}\right)$. After centrifugation $(3000 \mathrm{rpm}$, $15 \mathrm{~min})$, the precipitate was collected and deproteinated by the method of Miao et al. [20]. The polysaccharides content was measured by phenol-sulfuric acid method using glucose as a standard [21]. The percentage of AlAPS extraction yield was calculated according to the following formula:

$$
\text { AlAPS extraction yield }(\%)=\frac{W_{i}}{W_{o}} \times 100 \text {, }
$$

where $W_{i}$ was the polysaccharide weight of extraction (g) and $W_{o}$ represented dried sample weight $(\mathrm{g})$.

2.3. Purification of AlAPS. The lyophilized power of AlAPS $(2 \mathrm{~g})$ was dissolved in distilled water $(50 \mathrm{~mL})$ and fractionated on the DEAE-52 cellulose anion-exchange column $(1.6 \mathrm{~cm} \times$ $20 \mathrm{~cm}$ ) which was eluted with distilled water and then with gradient solutions of $\mathrm{NaCl}(0.1,0.3,0.5$, and $1.0 \mathrm{~mol} / \mathrm{L})$ at a flow rate of $2 \mathrm{~mL} /$ tube. The major polysaccharide fractions were determined by the phenol-sulfuric acid method [21] and lyophilized for further analysis.

2.4. Determination of Molecular Weight. The molecular weight was analyzed using previous method with some slight modifications [22]. The polysaccharides $(10 \mathrm{mg})$ were dissolved in distilled water $(2 \mathrm{~mL})$ and the molecular weight determination of AlAPS and its fractions were by high performance liquid chromatography (HPLC) which was operated with a HPLC system (1260, Agilent Technologies, USA) equipped with a SHODEX SB-806HQ column $(8.0 \mathrm{~mm} \times$ $300 \mathrm{~mm}$ ) and a refractive index detector. The injection volume was $20 \mu \mathrm{L}$. The deionized water was used as mobile phase at a flow rate of $0.5 \mathrm{~mL} / \mathrm{min}$, and the column temperature was maintained at $40^{\circ} \mathrm{C}$. A series of standard dextran compounds were used to make the calibration curve.

2.5. Analysis of Monosaccharide Composition. The monosaccharide composition was analyzed using our previous method with some slight modifications [23]. The purified fractions were hydrolyzed with trifluoroacetic acid (TFA) at $120^{\circ} \mathrm{C}$ for $4 \mathrm{~h}$, and the residual TFA was removed with methanol. The hydrolyzed substance was acetylated by hydroxylamine hydrochloride $(12 \mathrm{~mol} / \mathrm{L})$ and sodium borohydride (dissolved in ammonium hydroxide). The reaction solution $(1 \mu \mathrm{L})$ was injected into a capillary column of Rtx-1 $(30 \mathrm{~mm} \times 0.25 \mathrm{~mm} \times 0.25 \mu \mathrm{m})$. The relative molar ratios of monosaccharide were calculated by the area normalization method according to the standard chromatograms of glucose (Glu), fucose (Fuc), arabinose (Ara), xylose (Xyl), ribose (Rib), galactose (Gal), mannose (Man), and rhamnose (Rha).

2.6. Antioxidant Activities In Vitro. The scavenging rate on hydroxyl radicals was measured by the method of Smironff and Cumbes with slight modifications [24]. The hydroxyl radicals were generated in the mixture of ferrous sulfate $(1 \mathrm{~mL}$, $9 \mathrm{mmol} / \mathrm{L})$, salicylic acid $(1 \mathrm{~mL}, 9 \mathrm{mmol} / \mathrm{L})$, and hydrogen peroxide $(1 \mathrm{~mL}, 0.03 \%, \mathrm{v} / \mathrm{v})$. After addition of $1 \mathrm{~mL}$ polysaccharide samples $(0.1-1 \mathrm{mg} / \mathrm{mL})$, the mixture was incubated at 
$37^{\circ} \mathrm{C}$ for $30 \mathrm{~min}$. The absorbance of the mixture was measured at $510 \mathrm{~nm}$ using water as blank. The scavenging rate on hydroxyl radicals was calculated as follows, and the EC50 value $(\mathrm{mg} / \mathrm{mL})$ was the effective concentration at which the hydroxyl radicals were scavenged by $50 \%$.

$$
\text { Scavenging rate }(\%)=\left(1-\frac{A_{i}}{A_{o}}\right) \times 100 \text {, }
$$

where $A_{i}$ was the absorbance of the polysaccharide samples and $A_{o}$ was the absorbance of the blank.

The scavenging activity on DPPH radicals was assayed according to the method of Shimada et al. [25] with some modifications. Each sample $(2 \mathrm{~mL})$ was mixed with $2.0 \mathrm{~mL}$ $\mathrm{DPPH}(0.1 \mu \mathrm{mol} / \mathrm{L})$ or ethanol $(95 \%, \mathrm{w} / \mathrm{v})$ to a final volume of $4 \mathrm{~mL}$, using distilled water $(1 \mathrm{~mL})$ as contrast of samples. The mixtures were shaken vigorously and left still for $30 \mathrm{~min}$ in the dark, and the absorbance was measured at $517 \mathrm{~nm}$ against ethanol as a blank. The scavenging ability was calculated as follows, and the EC50 value $(\mathrm{mg} / \mathrm{mL})$ was the effective concentration at which the DPPH radicals were scavenged by $50 \%$.

$$
\text { Scavenging ability }(\%)=1-\frac{\left(A_{i}-A_{j}\right)}{A_{o}} \times 100 \text {, }
$$

where $A_{o}$ was the absorbance of mixture containing DPPH and ethanol, $A_{i}$ was the absorbance of mixture containing samples and DPPH, and $A_{j}$ was the absorbance of mixture containing samples and ethanol, respectively.

The reducing power was determined according to the reported method with slight modification [22]. Each sample $(1 \mathrm{~mL})$ was mixed with $2.5 \mathrm{~mL}$ phosphate buffer $(0.2 \mathrm{~mol} / \mathrm{L}$, $\mathrm{pH} 6.6$ ), and $2.5 \mathrm{~mL}$ potassium hexacyanoferrate solution $(1 \%, \mathrm{w} / \mathrm{v})$. The mixtures were incubated $20 \mathrm{~min}$ at $50^{\circ} \mathrm{C}$. After the reaction was cooled in flowing water, $2.5 \mathrm{~mL}$ trichloroacetic acid $(10 \%, \mathrm{w} / \mathrm{v}), 2.5 \mathrm{~mL}$ distilled water, and $2.5 \mathrm{~mL}$ ferric chloride $(0.1 \%$, w/v) were added successively. Immediately, the absorbance of the reaction mixture was measured at $700 \mathrm{~nm}$. The EC50 value $(\mathrm{mg} / \mathrm{mL})$ was the effective concentration at which the reducing power was 0.5 .

The chelating effect on $\mathrm{Fe}^{2+}$ was measured according to the referenced method [26] with some modifications. Briefly, the reaction mixture, containing $2 \mathrm{~mL}$ of sample, $0.1 \mathrm{~mL}$ of ferrous chloride $\left(\mathrm{FeCl}_{2}\right), 0.4 \mathrm{~mL}$ of ferrozine solution $(5 \mathrm{mmol} / \mathrm{L})$, and $5 \mathrm{~mL}$ of distilled water, was shaken well and incubated for $10 \mathrm{~min}$ at room temperature. The absorbance of the mixture was determined at $562 \mathrm{~nm}$ and the $\mathrm{Fe}^{2+}$-chelating activity was calculated according to the following formula:

$$
\mathrm{Fe}^{2+} \text {-chelating activity }(\%)=\frac{\left(A_{o}-A_{j}\right)}{A_{o}} \times 100
$$

where $A_{o}$ was the absorbance of the polysaccharide samples and $A_{j}$ was the absorbance of the blank. The $\mathrm{EC}_{50}$ value $(\mathrm{mg} / \mathrm{mL})$ was the effective concentration at which the $\mathrm{Fe}^{2+}$ chelating activity was $50 \%$.
2.7. Animal Experiments. The male Kunming mice $(20 \pm$ $2 \mathrm{~g}$, purchased from Taibang Biological Products Inc., Tai'an, China) were acclimated to new conditions for 7 days with free access to food and water ad libitum at a temperature of $20-25^{\circ} \mathrm{C}$ under a $12 \mathrm{~h}$ light/dark cycle. All experiments were performed in accordance with the Regulations of Experimental Animal Administration issued by the State Committee of Science and Technology of the People's Republic of China.

The mice were randomly divided into eleven groups (five mice in each group) including three control groups of normal control (NC), model control (MC), and vitamin $\mathrm{C}$ positive control (PC), as well as eight dose groups of four high levels groups $(400 \mathrm{mg} / \mathrm{kg})$ and four low levels groups $(200 \mathrm{mg} / \mathrm{kg})$. Mice in low group and high group were orally fed with doses of 200 and $400 \mathrm{mg} / \mathrm{kg}$ of mice by filling the stomach $(0.01 \mathrm{~mL} / \mathrm{g})$ with a syringe and $\mathrm{D}$-galactose intraperitoneal injection $(200 \mathrm{mg} / \mathrm{kg})$, respectively. The mice in NC groups were treated with the same volume of physiological saline solution $(0.9 \%, \mathrm{w} / \mathrm{v})$. The mice in the MC groups were treated with the same volume of saline and D-galactose $(200 \mathrm{mg} / \mathrm{kg})$ intraperitoneal injection. The positive group was treated with the same volume of Vc $(200 \mathrm{mg} / \mathrm{kg})$ and D-galactose $(200 \mathrm{mg} / \mathrm{kg})$ intraperitoneal injection.

After a 30-day successive experiment, all mice were sacrificed by cervical dislocation. The blood was collected and centrifuged (10000 rpm, $4^{\circ} \mathrm{C}$ ) for $10 \mathrm{~min}$ to obtain serum. The alanine aminotransferase (ALT) activity, aspartate aminotransferase (AST) activity, alkaline phosphatase (ALP) activity, albumin (ALB) levels, high density lipoprotein cholesterol (HDL-C) levels, and low density lipoprotein cholesterol (LDL-C) levels in serum were measured using automatic biochemical analyzer (ACE, USA).

The liver was surgically excised, accurately weighed, and homogenized $(1: 9, \mathrm{w} / \mathrm{v})$ immediately in normal saline and ethyl alcohol. The homogenates were centrifuged (4000 rpm) at $4^{\circ} \mathrm{C}$ for $20 \mathrm{~min}$, and the supernatant was obtained for analyzing the activities of SOD, GSH-Px, CAT, and T-AOC, as well as contents of MDA and LPO by the commercial reagent kits according to the instructions.

2.8. Statistical Analysis. All data were expressed as means \pm standard deviation (SD). Statistical analyses were performed by one-way ANOVA using the SPSS statistical package (SPSS Inc. Chicago, USA). Statistical significance was considered as $P<0.05$

\section{Results}

3.1. Isolation and Purification of AlAPS. In present work, the yield of AlAPS was $4.31 \pm 0.25 \%$. The chromatography results of AlAPS were shown in Figure 1. Obviously, three major peaks, named as AlAPS-1, AlAPS-2, and AlAPS-3, were purified by DEAE-52 chromatography. Detailedly, the AlAPS-1 was neutral polysaccharides since it was eluted by distilled water, while the AlAPS- 2 and AlAPS- 3 were acidic polysaccharides since they were eluted by $0.1-0.5 \mathrm{~mol} / \mathrm{L}$ $\mathrm{NaCl}$ solutions [27]. All the fragments were selected for the evaluation of antioxidant activities in vitro and in vivo. 


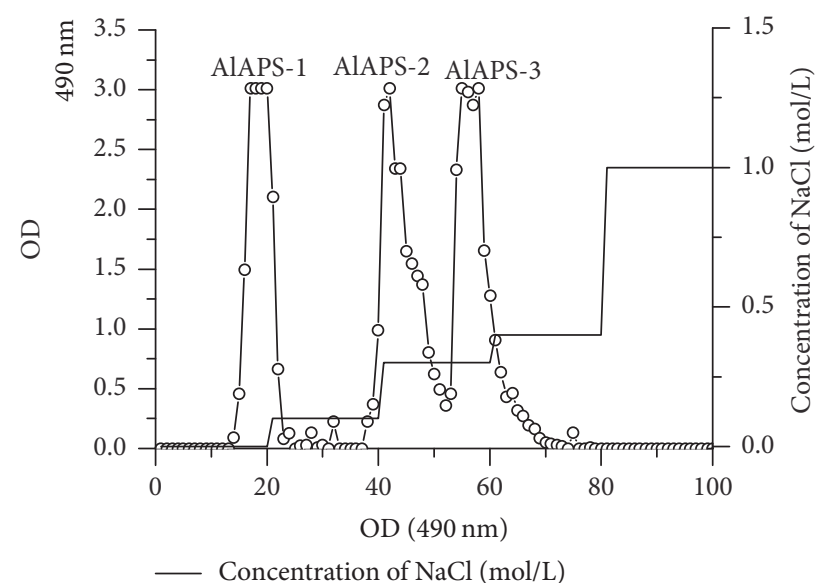

FIGURE 1: Elution profiles on DEAE-52 chromatography of AlAPS.

TABLE 1: Molecular weights of AlAPS.

\begin{tabular}{lc}
\hline & $\mathrm{Mw}, \times 10^{4} \mathrm{Da}$ \\
\hline AlAPS & 3.47 \\
AlAPS-1 & 5.32 \\
AlAPS-2 & 2.53 \\
AlAPS-3 & 7.96 \\
\hline
\end{tabular}

3.2. Molecular Weight of AlAPS. According to the retention time, the molecular weight distribution of AlAPS polysaccharide was $3.47 \times 10^{4} \mathrm{Da}$. The molecular weights distribution of AlAPS-1, AlAPS-2, and AlAPS- 3 were $5.32 \times 10^{4} \mathrm{Da}, 2.53 \times$ $10^{4} \mathrm{Da}$, and $7.96 \times 10^{4} \mathrm{Da}$, respectively (Table 1 ).

3.3. Monosaccharide Composition. The monosaccharide compositions of AlAPS and its three purified fractions (AlAPS-1, AlAPS-2, and AlAPS-3) were shown in Figure 2. The monosaccharides in all samples were identified by comparing the retention times with those of standards (Figure 2(a)). As shown in Figure 2(b), AlAPS contained Fuc, Rib, Xyl, Man, Gal, and Glu in a mass percentage of $12.96 \%, 0.58 \%, 1.16 \%, 2.2 \%, 28.82 \%$, and $54.28 \%$. As for its three fractions, AlAPS-1 was composed of Fuc (11.39\%), Rib (0.61\%), Xyl (5.98\%), Man (7.89\%), Gal (43.06\%), and Glu (31.06\%) with the molar ratio of $16.5: 1: 7.9: 10.5: 57: 45.1$ (Figure 2(c)), the AlAPS-2 was composed of Fuc, Rib, Xyl, Man, Gal, and Glu in a mass percentage of $6.81 \%$, $1.98 \%, 2.29 \%, 37.39 \%, 22.31 \%$, and $29.23 \%$ with the molar ratio of $3.3: 1.1: 1: 16.6: 9.9: 14.3$ (Figure 2(d)), while AlAPS-3 was composed of Rib (4.4\%), Man (6.97\%), Gal (22.94\%), and Glu (65.69\%) with a molar ratio of $1: 1.7: 8.5: 24.3$ (Figure 2(e)). The results indicated that the three fractions were heteropolysaccharides, Gal and Glu were the predominant monosaccharides in AlAPS, AlAPS-1, and AlAPS-3, and Man and Glu were the major monosaccharide in AlAPS-2.
3.4. Antioxidant Activities In Vitro. In this work, four parameters including reducing power, ferrous ions chelating activity, and scavenging activities on hydroxyl radicals and DPPH radicals were collected to analyze the in vitro antioxidant of AlAPS and its fractions, and the results were shown in Figure 3.

As shown in Figure 3(a), AlAPS, AlAPS-1, AlAPS-2 and AlAPS-3 expressed the markedly increased scavenging activities on hydroxyl radical dose-dependently. The scavenging activities of AlAPS-2 $(85.78 \pm 2.85 \%)$ showed considerably stronger effectivities $(P<0.05)$ than that of AlAPS (62.57 $\pm 3.58 \%)$, AlAPS-1 (54.67 $\pm 2.77 \%)$, and AlAPS-3 (49.53 $\pm 1.65 \%)$ at a dose of $1.0 \mathrm{mg} / \mathrm{mL}$, respectively. Besides, the EC50 values of AlAPS, AlAPS-1, AlAPS-2, and AlAPS-3 for scavenging hydroxyl radical activity were $0.59 \pm 0.23,1.06 \pm$ $0.03,0.23 \pm 0.07$, and $1.51 \pm 0.18 \mathrm{mg} / \mathrm{mL}$, respectively.

The scavenging effects of polysaccharides on the DPPH radicals were shown in Figure 3(b). Apparently, both AlAPS and its purified fractions had obvious scavenging effects against DPPH radicals in concentration-dependent manners. Within the tested concentrations of $0-1.0 \mathrm{mg} / \mathrm{mL}$, the scavenging activities of the AlAPS-2 (65.47 $\pm 1.98 \%)$ were higher than that of AlAPS, AlAPS-1, and AlAPS-3. The results were supported by EC50 values, which were found to be 0.67 $\pm 0.17 \mathrm{mg} / \mathrm{mL}$ for AlAPS, $1.11 \pm 0.05 \mathrm{mg} / \mathrm{mL}$ for AlAPS- 1 , $0.305 \pm 0.05 \mathrm{mg} / \mathrm{mL}$ for AlAPS-2, and $1.46 \pm 0.17 \mathrm{mg} / \mathrm{mL}$ for AlAPS-3.

Figure 3(c) showed the reducing power of polysaccharides. When the polysaccharides concentrations raised from 0 to $1.0 \mathrm{mg} / \mathrm{mL}$, the reducing power of AlAPS, AlAPS-1, AlAPS2 , and AlAPS- 3 was $0.459 \pm 0.05,0.231 \pm 0.11,0.753 \pm 0.08$, and $0.098 \pm 0.13$, respectively, indicating that the AlAPS2 had superior antioxidant activities than AlAPS, AlAPS1 , and AlAPS-3 in vitro. The EC50 values of AlAPS-2 (1.21 $\pm 0.08 \mathrm{mg} / \mathrm{mL}$ ) indicated that AlAPS-2 possessed stronger reducing power than AlAPS $\left(\mathrm{EC}_{50}=2.14 \pm 0.33 \mathrm{mg} / \mathrm{mL}\right.$ ), AlAPS-1 $\left(\mathrm{EC}_{50}=3.78 \pm 0.58 \mathrm{mg} / \mathrm{mL}\right)$, and AlAPS-3 $\left(\mathrm{EC}_{50}=\right.$ $4.66 \pm 0.67 \mathrm{mg} / \mathrm{mL})$.

For the $\mathrm{Fe}^{2+}$-chelating activity, as exhibited in Figure 3(d), both AlAPS and its purified fractions showed dosedependent manners and presented a smooth growth within the concentrations of $0-1.0 \mathrm{mg} / \mathrm{mL}$. At the concentration of $1.0 \mathrm{mg} / \mathrm{mL}$, the $\mathrm{Fe}^{2+}$-chelating rate of AlAPS, AlAPS-1, AlAPS-2, and AlAPS- 3 was $58.53 \pm 1.08 \%, 49.08 \pm 2.01 \%$, $76.68 \pm 1.68 \%$, and $44.79 \pm 0.88 \%$, respectively, indicating that AlAPS had potential antioxidant activities in chelating $\mathrm{Fe}^{2+}$. Additionally, the EC50 values of AlAPS, AlAPS-1, AlAPS-2, and AlAPS-3 were $1.69 \pm 0.23,2.85 \pm 0.46,0.85 \pm 0.07$, and $3.65 \pm 0.56 \mathrm{mg} / \mathrm{mL}$, respectively.

3.5. Antiaging Activities Assaying. As shown in Figure 4, the hepatic activities of SOD, GSH-Px, CAT, and T-AOC of mice in the $\mathrm{MC}$ groups were significantly decreased when compared with that in the NC groups $(P<0.01)$, indicating that the aging models were successfully established. In this work, the hepatic activities of SOD, GSH-Px, CAT, and T-AOC were expressed dose-dependently manners by the treatment with AlAPS and its purified fractions at the tested 


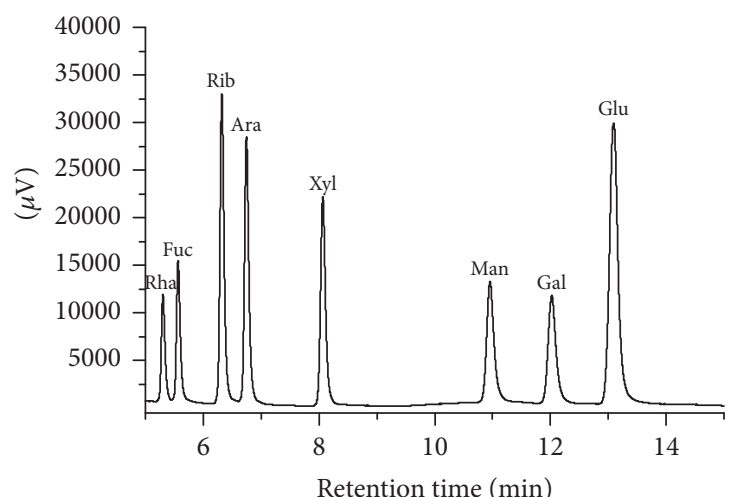

(a)

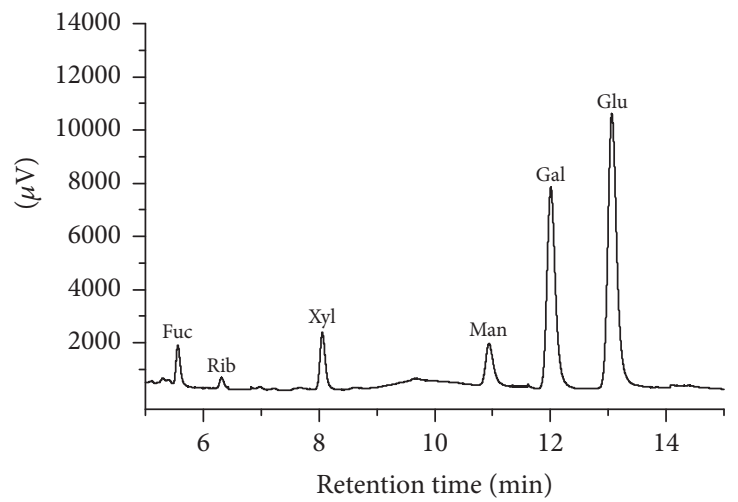

(c)

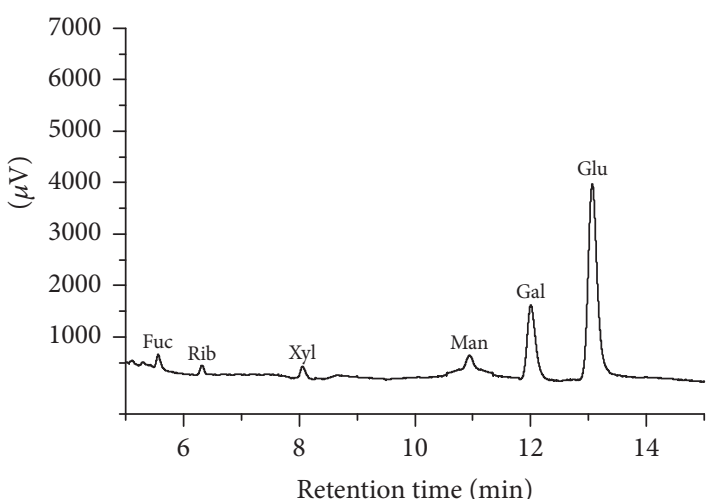

(b)

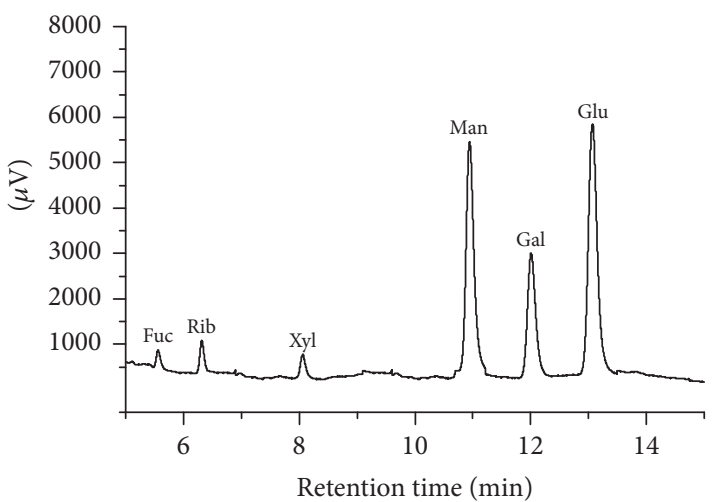

(d)

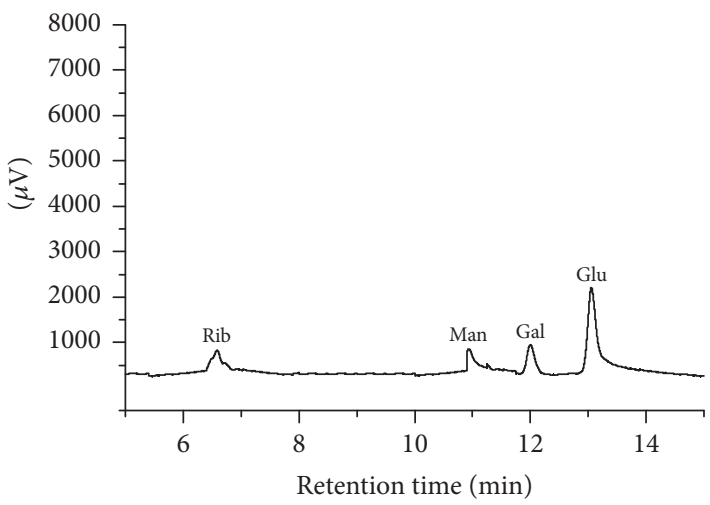

(e)

FIGURE 2: Gas chromatographs of (a) standard monosaccharides, (b) AlAPS, (c) AlAPS-1, (d) AlAPS-2, and (e) AlAPS-3.

doses of 200 and $400 \mathrm{mg} / \mathrm{kg}$. As shown in Figure 4(a), in the high levels of AlAPS-2 groups, the SOD activities reached $151.65 \pm 13.58 \mathrm{U} / \mathrm{mg}$ prot, which was higher than that of AlAPS (124.27 $\pm 10.54 \mathrm{U} / \mathrm{mg}$ prot), AlAPS-1 (132.87 $\pm 11.34 \mathrm{U} / \mathrm{mg}$ prot), and AlAPS-3 (118.72 $\pm 10.53 \mathrm{U} / \mathrm{mg}$ prot), respectively. As shown in Figure 4(b), significant increases in GSH-Px activities were observed after the administration of AlAPS, AlAPS-1, AlAPS-2, and AlAPS-3 at two doses of $200 \mathrm{mg} / \mathrm{kg}(81.34 \pm 2.52,87.48 \pm 4.57,90.41 \pm 5.07$, and $80.65 \pm 3.58 \mathrm{U} / \mathrm{mg}$ prot $)$ and $400 \mathrm{mg} / \mathrm{kg}(90.67 \pm 5.73,94.72$ $\pm 6.47,101.35 \pm 8.24$, and $87.68 \pm 6.98 \mathrm{U} / \mathrm{mg}$ prot) when compared with that in the MC groups $(70.65 \pm 8.32 \mathrm{U} / \mathrm{mg}$ prot). Figure 4(c) showed that the CAT activities in the mice treated with AlAPS, AlAPS-1, AlAPS-2, and AlAPS-3 reached $213.45 \pm 10.54,221.34 \pm 11.02,235.64 \pm 15.14$, and $198.42 \pm 9.45 \mathrm{U} / \mathrm{mg}$ prot at the dosage of $400 \mathrm{mg} / \mathrm{kg}$, which were significantly higher than that in MC groups (124.72 \pm $8.44 \mathrm{U} / \mathrm{mg}$ prot, $P<0.01)$ and were almost approximate to that in the PC groups $(219.43 \pm 10.42 \mathrm{U} / \mathrm{mg}$ prot $)$. In the high dose of AlAPS-2 groups, the activities of T-AOC reached the maximum of $69.73 \pm 5.34 \mathrm{U} / \mathrm{mg}$ prot, which were significantly higher than those of AlAPS (59.43 $\pm 4.23 \mathrm{U} / \mathrm{mg}$ prot), AlAPS$1(62.82 \pm 4.97 \mathrm{U} / \mathrm{mg}$ prot $)$, and AlAPS-3 $(55.87 \pm 4.07 \mathrm{U} / \mathrm{mg}$ prot) at the dose of $400 \mathrm{mg} / \mathrm{kg}$, respectively (Figure $4(\mathrm{~d})$ ). Meanwhile, at a dose of $200 \mathrm{mg} / \mathrm{kg}$, the mice in PC groups with Vc treatment also manifested significant increases of 


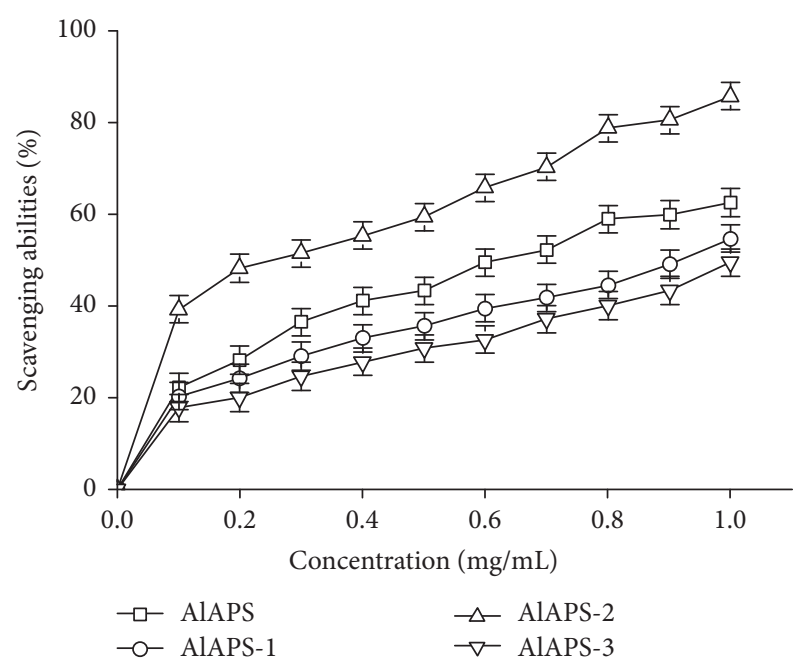

(a)

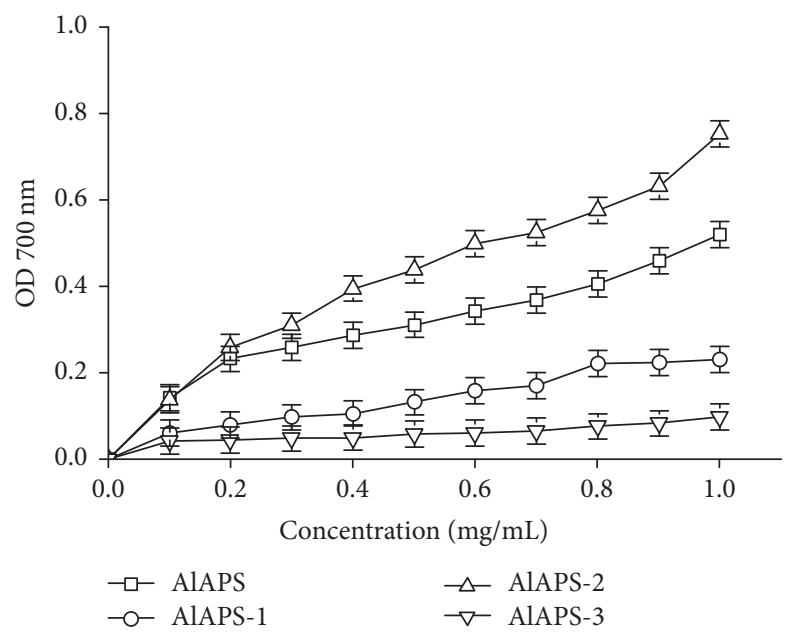

(c)

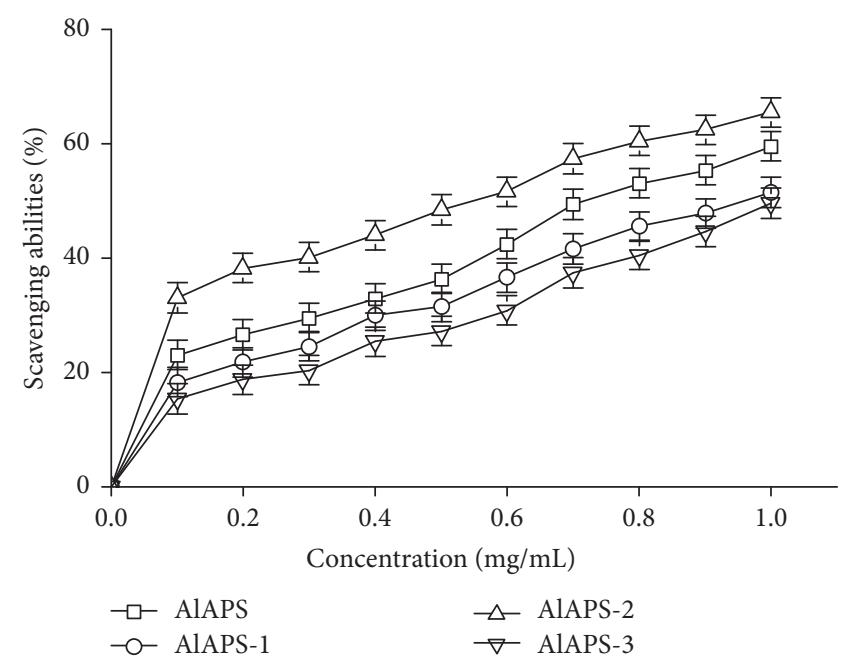

(b)

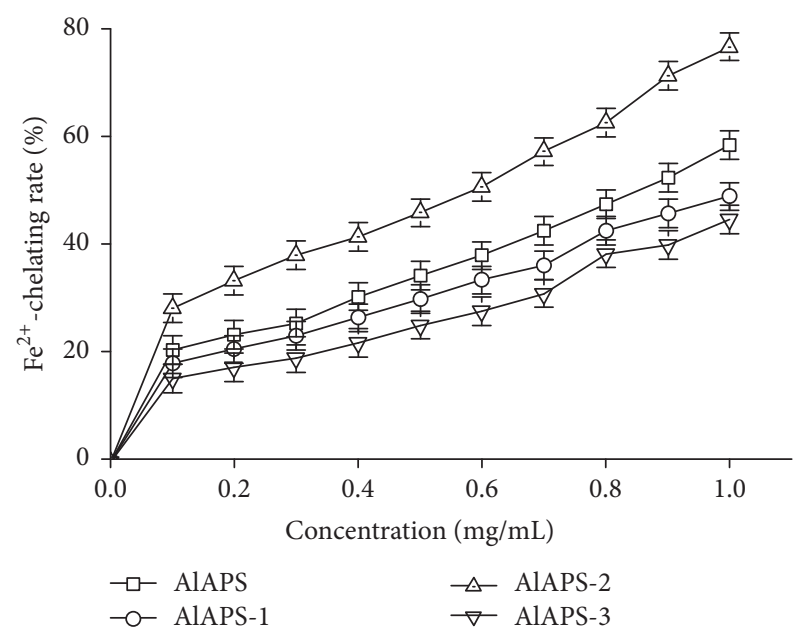

(d)

FIgure 3: Antioxidant activities of AlAPS, AlAPS-1, AlAPS-2, and AlAPS-3 in vitro. (a) Hydroxyl radicals, (b) DPPH radicals, (c) reducing power, and (d) $\mathrm{Fe}^{2+}$-chelating rate.

the SOD, GSH-Px, CAT, and T-AOC activities against Dgalactose induced aging.

As illustrated in Figures 4(e) and 4(f), the hepatic contents of MDA and LPO were significantly increased $(P<0.01)$ in the D-galactose induced aging mice when compared with that in the NC groups. Interestingly, AlAPS and its fractions significantly suppressed the contents of MDA and LPO dose-dependently. As shown in Figure 4(e), the MDA contents of AlAPS-2 in liver reduced to $5.94 \pm 0.11 \mu \mathrm{mol} / \mathrm{mg}$, which was about $52.63 \%$ lower than that of MC groups when compared with that in the MC groups $(12.07 \pm 0.23 \mu \mathrm{mol} / \mathrm{mg})$, and almost approximate to that in the NC groups (5.85 $\pm 0.15 \mu \mathrm{mol} / \mathrm{mg}$ ), respectively. As shown in Figure 4(f), the LPO contents of AlAPS-2 at the dose of $400 \mathrm{mg} / \mathrm{kg}$ reached $6.06 \pm$ $0.15 \mathrm{nmol} / \mathrm{mg}$ prot $(P<0.01)$, lower than those in other dose groups, respectively. The positive group also demonstrated the significant effect compared with MC group $(P<0.01)$.
In this work, these data indicated that AlAPS and its purified fractions had potential antiaging effects by improving SOD, GSH-Px, CAT, and T-AOC activities, as well as reducing MDA and LPO contents in the liver tissue against $\mathrm{D}$-galactose induced aging.

3.6. Biochemical Assays in Serum. Several enzymes in serum such as ALT, AST, and ALP were usually used as biochemical markers of liver damage. As displayed in Figure 5, when compared with that in the NC groups, the mice in MC groups showed serious liver damage as evidenced by significant increases in the activities of ALT, AST, and ALP, as well as levels of ALB (with all $P<0.01$ ). As shown in Figure 5(a), The ALT activities reached $50.9 \pm 3.5 \mathrm{U} / \mathrm{L}(P<0.01)$ in AlAPS2 group at the dosage of $400 \mathrm{mg} / \mathrm{kg}$, which were lower than that in MC groups $(108.5 \pm 5.4 \mathrm{U} / \mathrm{L}, P<0.01)$. As for AST and ALP, the minimum activities reached $140.1 \pm 7.5 \mathrm{U} / \mathrm{L}$ and $112.1 \pm 8.3 \mathrm{U} / \mathrm{L}$, which were significantly lower than that in 


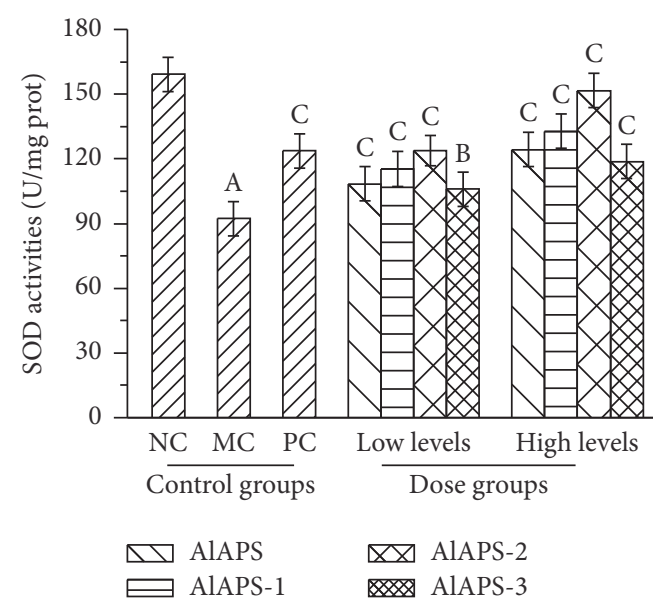

(a)

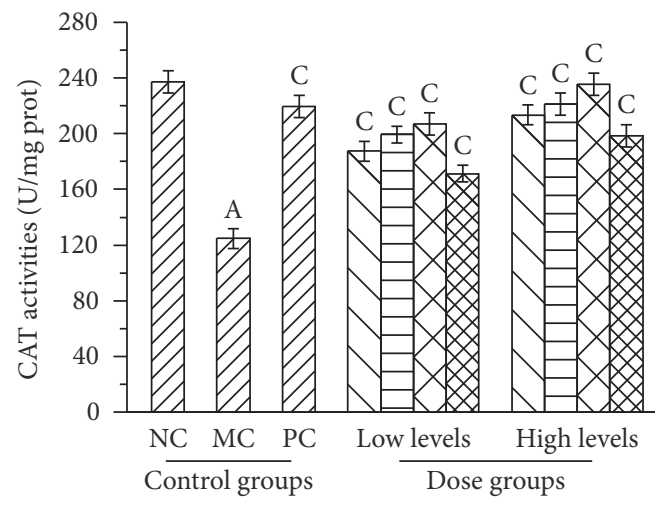

$\square$ AlAPS $\square \times$ AlAPS-2

$\rightleftarrows$ AlAPS-1 AlAPS-3 $^{2}$

(c)

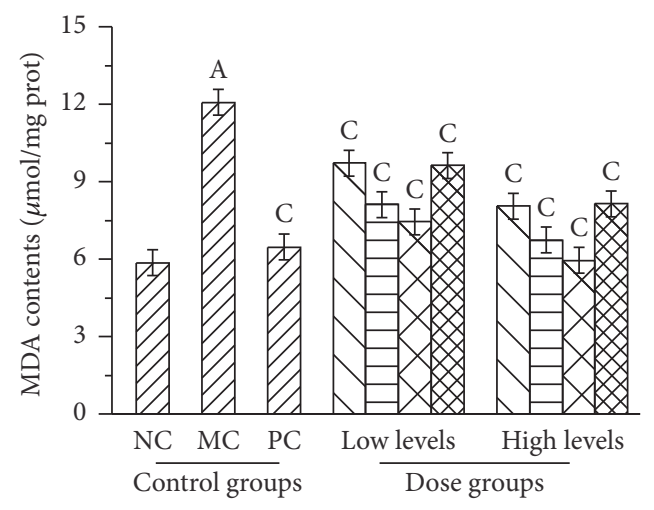

$\begin{array}{lll}\square & \text { AlAPS } & \text { AlAPS-2 } \\ \rightleftharpoons \text { AlAPS-1 } & \text { AlAPS-3 }\end{array}$

(e)

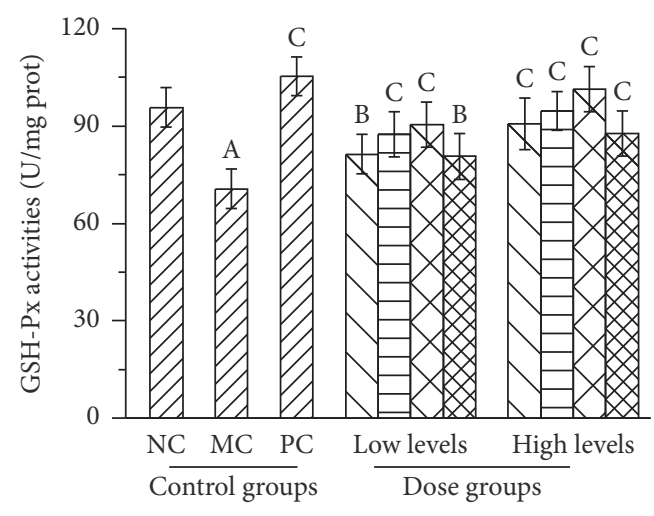

$\begin{array}{ll}\square \text { AlAPS } & \square \text { AlAPS-2 } \\ \square \text { AlAPS-1 } & \text { AlAPS-3 }\end{array}$

(b)

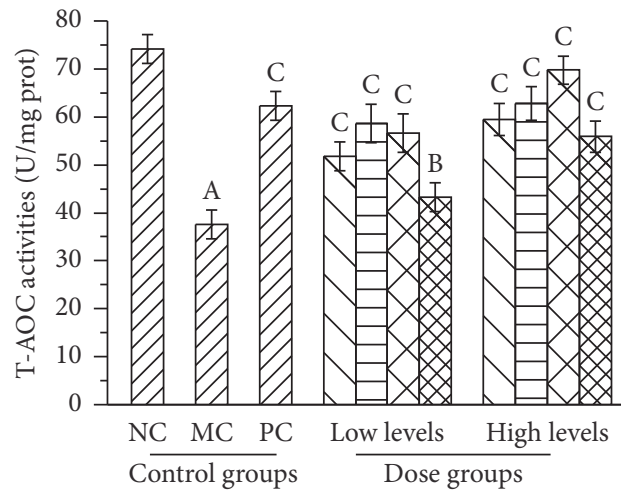

$\triangle \square$ AlAPS $\square \square$ AlAPS-2

AlAPS-1 AlAPS-3

(d)

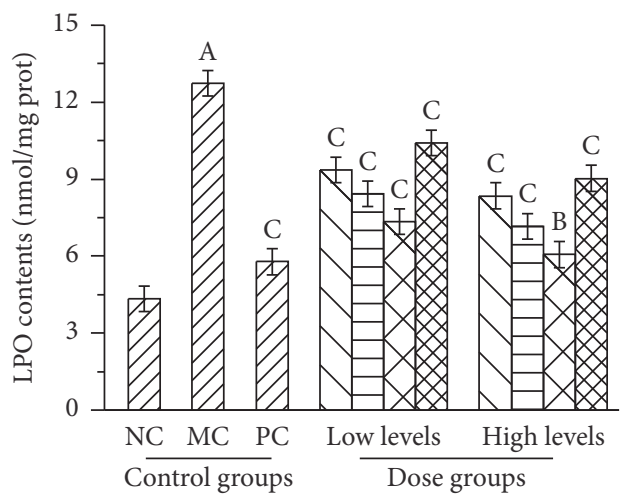

$\begin{array}{ll}\square \text { AlAPS } & \square \text { AlAPS-2 } \\ \rightleftharpoons \text { AlAPS-1 } & \text { AlAPS-3 }\end{array}$

(f)

FIgure 4: Effects of AlAPS, AlAPS-1, AlAPS-2, and AlAPS-3 on the hepatic activities of (a) SOD, (b) GSH-Px, (c) CAT, and (d) T-AOC, as well as contents of (e) MDA and (f) LPO. The values are reported as the mean \pm SD of five mice per group. ${ }^{\mathrm{A}} P<0.01$ compared with NC groups; ${ }^{\mathrm{B}} \mathrm{P}<0.05$ and ${ }^{\mathrm{C}} \mathrm{P}<0.01$ compared with the $\mathrm{MC}$ groups. 


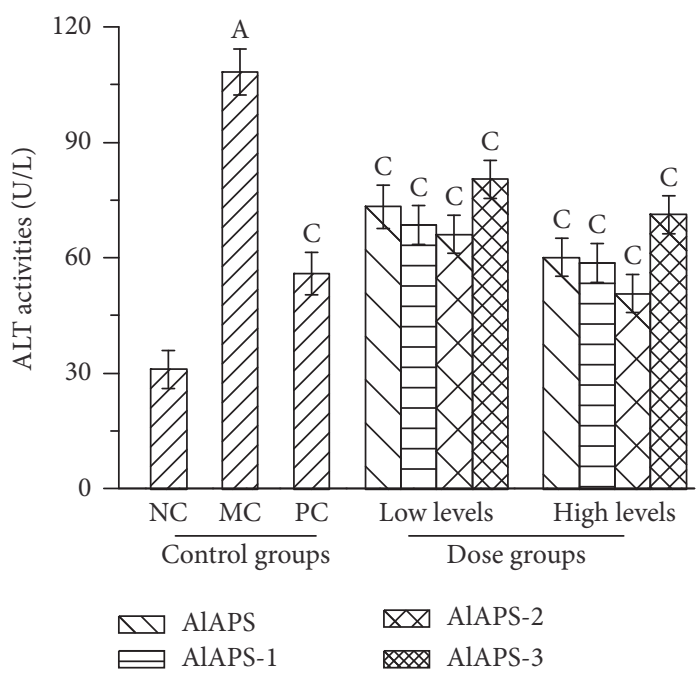

(a)
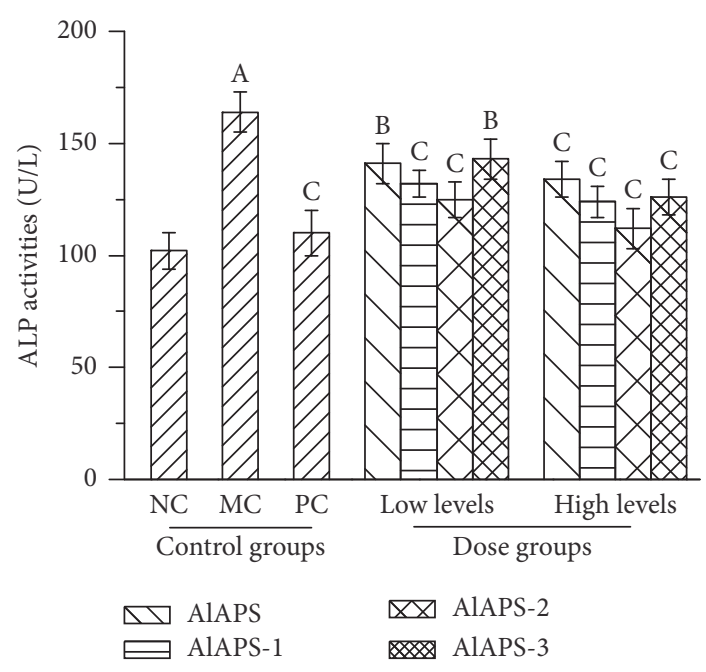

(c)

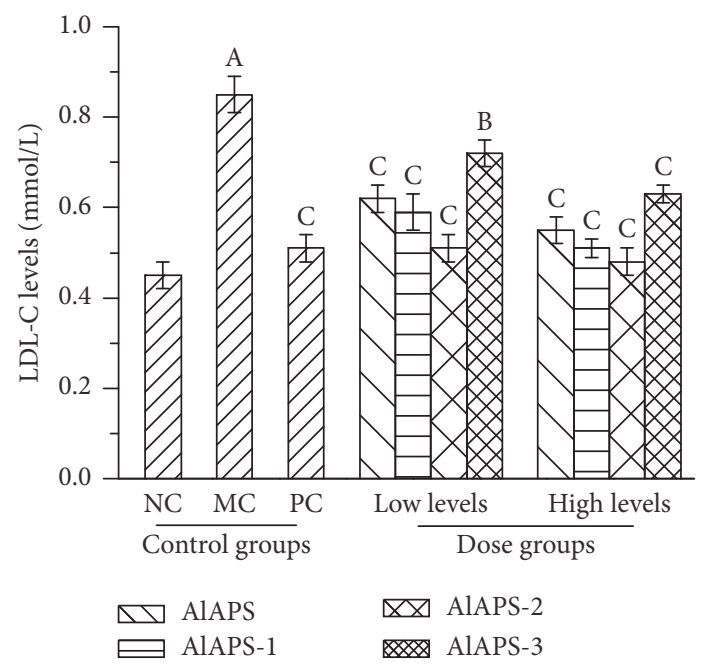

(e)

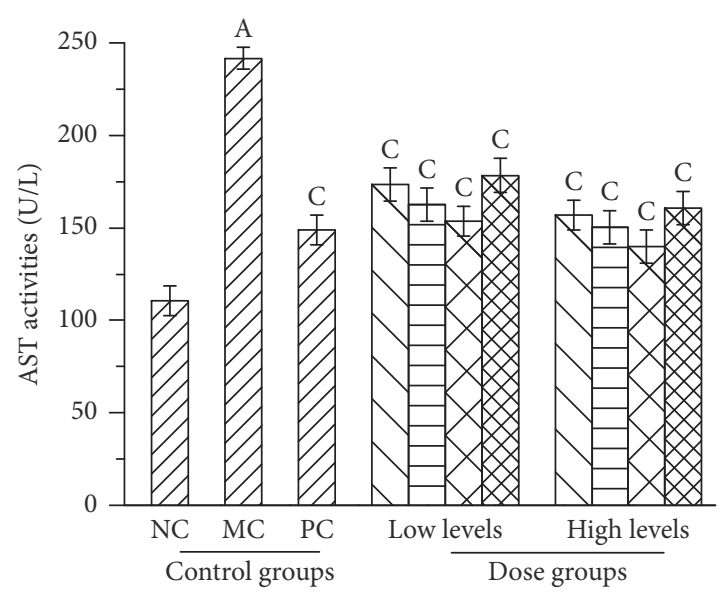

$\begin{array}{ll}\square \text { AlAPS } & \square \text { AlAPS-2 } \\ \rightleftharpoons \text { AlAPS-1 } & \text { AlAPS-3 }\end{array}$

(b)

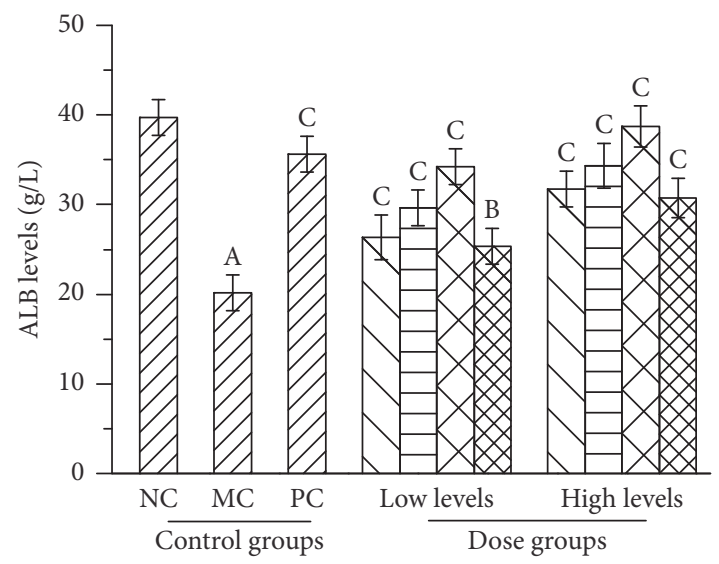

$\triangle \triangle$ AlAPS-2

AlAPS-3

(d)

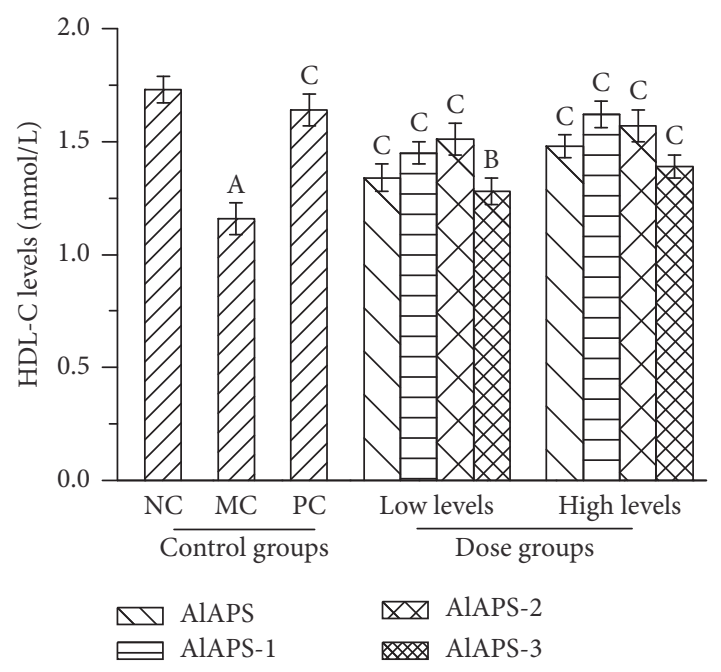

(f)

FIgure 5: Effects of AlAPS, AlAPS-1, AlAPS-2, and AlAPS-3 on (a) ALT activities, (b) AST activities, (c) ALP activities, (d) ALB levels, (e) LDL-C levels, and (f) HDL-C levels in D-galactose induced aging mice. The values are reported as the mean \pm SD of five mice per group. ${ }^{\mathrm{A}} P<0.01$ compared with NC groups; ${ }^{\mathrm{B}} \mathrm{P}<0.05$ and ${ }^{\mathrm{C}} P<0.01$ compared with the MC groups. 
MC groups $(241.6 \pm 12.5 \mathrm{U} / \mathrm{L}$ and $164.3 \pm 9.3$, Figures 5 (b) and 5(c), both $P<0.01$ ), respectively. Figure 5(d) showed that the levels of ALB in the D-galactose induced aging mice were significantly higher than those in the MC groups (20.15 $\pm 0.83 \mathrm{~g} / \mathrm{L}, P<0.01)$. Furthermore, the AlAPS-2 (38.69 \pm $2.05 \mathrm{~g} / \mathrm{L}$ ) showed superior effects when compared to AlAPS $(31.72 \pm 1.63 \mathrm{~g} / \mathrm{L})$, AlAPS-1 $(34.31 \pm 1.34 \mathrm{~g} / \mathrm{L})$, and AlAPS-3 $(30.78 \pm 0.96 \mathrm{~g} / \mathrm{L})$ at a dose of $400 \mathrm{mg} / \mathrm{kg}$, respectively. Meanwhile, the Vc at a dose of $200 \mathrm{mg} / \mathrm{kg}$ demonstrated significant antiaging effects against D-galactose. The results indicated that supplementation with AlAPS and its fractions had potential protection on aging liver by depressing the activities of ALT, AST, and ALP, as well as levels of ALB. As Figures 5(e) and 5(f) displayed, significant reductions of HDL-C levels and significant elevations of LDL-C levels were observed in MC groups as compared to the NC groups $(P<0.01)$. The LDL-C levels in group of AlAPS- 2 at $400 \mathrm{mg} / \mathrm{kg}$ were 0.48 $\pm 0.03 \mathrm{mmol} / \mathrm{L}$, which was lower than that in MC groups (Figure 5(e), $P<0.01$ ). As shown in Figure 5(f), in the dosage groups of $400 \mathrm{mg} / \mathrm{kg}$ treated with AlAPS-1, the HDL-C levels were $1.62 \pm 0.07 \mathrm{mmol} / \mathrm{L}$, which was more approximate to that in the PC group. These results signified that AlAPS and its purified fractions had potential effects in amelioration of liver damage.

\section{Discussion}

In recent years, aqueous extraction of polysaccharides from A. bisporus fruiting bodies, which were reported to possess a significantly antioxidant activity, have been receiving more and more attentions [18]. Nevertheless, few studies have focused on the alkali-extractable polysaccharides from A. bisporus fruiting bodies. The present study exhibited that AlAPS were considered as representative heteropolysaccharides due to the elution purified by DEAE- 52 cellulose column and gas chromatograph.

A review of recent literatures had revealed that the agingrelated hepatoprotective activities of natural substances were related to antioxidant and free radical scavenging activities $[28,29]$. The overproduction of ROS, including superoxide anion radical, hydroxyl radical, hydrogen peroxide, reactive oxygen, DPPH radicals, and nitrogen species, could result in oxidative stress, leading to the chemical modification of key cellular components, DNA instability, the membrane integrity, and decline in enzymatic activities [30]. Previous literatures had reported that the hydroxyl radicals, as the main reactive oxygen species in biological tissues, can react with most bimolecular compounds including amino acids, lipids, and DNA, causing the general aging processes of tissue damage [10]. Experimentally, the DPPH-based assay system was a rapid and efficient method for measuring the free radical scavenging activities of natural compounds; the possible mechanism may be that DPPH radicals could accept an electron/hydrogen to become a stable diamagnetic molecule, with the reduced absorbance [31]. The reducing capacity of a compound may serve as a significant indicator of its potential antioxidant activity, contributing to the potential breaking effects on the free radical chain [32,
33]. Furthermore, the nonenzymatic metal of $\mathrm{Fe}^{2+}$ chelating may be considered as an important antioxidant property by retarding the metal-catalyzed oxidation [34]. In present work, AlAPS-2 showed stronger scavenging abilities than AlAPS and other fractions on hydroxyl and DPPH radicals. Similar results were also observed on $\mathrm{Fe}^{2+}$-chelating abilities and reducing power. Previous research had reported that the molecular weight of polysaccharides was an important parameter, which could influence the antioxidant activity [35]. The AlAPS and AlAPS-2 with the lower molecular weights showed higher antioxidant activities, indicating that a relatively low molecular weight may enhance the antioxidant activity. Our results were also confirmed by Chen et al. [35]. Additionally, several literatures have reported that the antioxidant properties of polysaccharides were mainly associated with their monosaccharide compositions [36]. As shown in monosaccharide analysis, Gal and Glu were the predominant monosaccharides in AlAPS, AlAPS-1, and AlAPS-3, Man and Glu were the major monosaccharides in AlAPS-2, which is in agreement with the in vivo antioxidant activities, and Man was monitored in AcAPS-2, indicating that Man may play important roles in maintaining the aging effects.

Clinically, the activities of ALT, AST, and ALP in serum had been used as biochemical markers for liver damage, which could be leached out of hepatocytes into blood circulation when the permeability of cell membrane is damaged. When liver damage occurred, the enzymes activities were markedly heightened in serum [37]. Our results demonstrated that D-galactose induced aging showed serious liver damage as evidenced by significant elevations of the ALT, AST, ALP, and ALB. And the AlAPS and its fractions had hepatoprotective effects by stabilizing the plasma membrane as well as repairing the hepatic tissue damage. Increased HDL-C levels and decreased LDL-C levels were a curial advantage in improving hyperlipemia in oxidative stress mice [38]. These results suggested that both AlAPS and its purified fractions had potential inhibition against aging-induced liver injury.

According to the previous literatures, the $\mathrm{D}$-galactosemediated aging-toxicity at low dose has been widely used in applying for inducing aging properties by engendering lipid peroxidation and depletion of the antioxidant enzymes and eventually aging-related organic diseases of liver damage $[39,40]$. Antioxidant enzymes consisting of SOD, GSH$\mathrm{Px}$, and CAT, regarded as the first line of the antioxidant defense against ROS generated during the oxidative stress in vivo, were considered to be the primary defense that prevents biological macromolecules from potentially injurious oxidizing agents $[1,39]$. Briefly, the SOD showed potential antiaging effects by decomposing the superoxide radical to hydrogen peroxide [41]. Meanwhile, the GSH$\mathrm{Px}$, regarded as a selenium-containing enzyme against ROS, could directly react with ROS on preventing the formation of $\mathrm{H}_{2} \mathrm{O}_{2}$-induced hydroxyl radicals [1]. As a member of enzyme in the peroxisomes family, the CAT could facilitate the metabolism of hydrogen peroxide, resulting in the less-reactive substances of gaseous oxygen and water molecules [8]. Besides the enzymatic antioxidant systems, the nonenzymatic antioxidant systems (reflected by T-AOC 
activities presently) showed potential effects against the various ROS formation, increasing the susceptibility to oxidative damage $[42,43]$. In addition, both MDA and LPO, considered as the end products of lipid peroxidation, could be deemed to the hallmarks of oxidative stress causing aging and its applications (hepatic injuries) [21, 44, 45]. In this work, the D-galactose injection caused the serious oxidative stress reflected by the significant decreases of SOD, GSH-Px, CAT, and T-AOC activities, as well as significant increases of MDA and LPO contents in aging mice. Interestingly, the treatment with AlAPS and its fractions (AlAPS-1, AlAPS-2, and AlAPS3) remarkably enhanced the antioxidant enzyme activities and reduced the lipid peroxidation contents, indicating that the polysaccharides extracted and purified form A. bisporus could remit and improve the aging properties either by scavenging excessive free radicals or by promoting antioxidant enzyme activities.

\section{Conclusions}

In conclusion, both AlAPS and its purified fractions of AlAPS-1, AlAPS-2, and AlAPS-3 from A. bisporus have shown to be an excellent source of antioxidant, antiaging, and hepatoprotective polysaccharides against D-galactose induced aging in mice, which would be exploited as a potentially natural and functional food or a novel nutraceutical for the prevention and alleviation of aging and its complications.

\section{Abbreviations}

AlAPS: Alkali-extractable polysaccharides

ALP: Alkaline phosphatase

ALT: Alanine aminotransferase

Ara: Arabinose

AST: Aspartate aminotransferase

BUN: Blood urea nitrogen

CAT: Catalase

GC: Gas chromatography

CER: Ceruloplasmin

D-gal: D-Galactose

DPPH: 1,1-Diphenyl-2-picrylhydrazyl

Fuc: Fucose

Glu: $\quad$ Glucose

GSH-Px: GSH peroxide

HDL-C: High density lipoprotein cholesterol

$\mathrm{H}_{2} \mathrm{O}_{2}$ : Hydrogen peroxide

LDL-C: Low density lipoprotein cholesterol

LPO: Lipid peroxidation

Man: Mannose

MC: $\quad$ Model control

MDA: Malondialdehyde

NC: $\quad$ Normal control

PC: $\quad$ Positive control

prot: Protein

Rib: Ribose

Rha: Rhamnose

ROS: $\quad$ Reactive oxygen species

SOD: Superoxide dismutase
T-AOC: Total antioxidant capacity

Xyl: Xylose.

\section{Conflicts of Interest}

The authors declared that they had no conflicts of interest.

\section{Acknowledgments}

This work was supported by grants from Mushroom Technology System of Shandong Province (SDAIT-07-05) and Fundamental Research Funds for Central Non-Profit Scientific Institution (1610132016041).

\section{References}

[1] S. Govindan, E. E. R. Johnson, J. Christopher, J. Shanmugam, V. Thirumalairaj, and J. Gopalan, "Antioxidant and anti-aging activities of polysaccharides from Calocybe indica var. APK2," Experimental and Toxicologic Pathology, vol. 68, no. 6, pp. 329334, 2016.

[2] T. B. L. Kirkwood, "Understanding the odd science of aging," Cell, vol. 120, no. 4, pp. 437-447, 2005.

[3] J. Huangfu, J. Liu, Z. Sun et al., "Antiaging effects of astaxanthinrich alga haematococcus pluvialis on fruit flies under oxidative stress," Journal of Agricultural and Food Chemistry, vol. 61, no. 32, pp. 7800-7804, 2013.

[4] B. Harwell, "Biochemistry of oxidative stress," Biochemical Society Transactions, vol. 35, no. 5, pp. 1147-1150, 2007.

[5] L. Lin, F. Cui, J. Zhang et al., "Antioxidative and renoprotective effects of residue polysaccharides from Flammulina velutipes," Carbohydrate Polymers, vol. 146, pp. 388-395, 2016.

[6] D. Harman, "Aging: a theory based on free radical and radiation chemistry," Journal of Gerontology, vol. 11, no. 3, pp. 298-300, 1956.

[7] J.-H. Xiao, D.-M. Xiao, D.-X. Chen, Y. Xiao, Z.-Q. Liang, and J.-J. Zhong, "Polysaccharides from the medicinal mushroom cordyceps taii show antioxidant and immunoenhancing activities in a D -galactose-induced aging mouse model," Evidencebased Complementary and Alternative Medicine, vol. 2012, Article ID 273435, 2012.

[8] W. Hu, D. Dai, and W. Li, "Anti-aging effect of Blakeslea trispora powder on adult mice," Biotechnology Letters, vol. 35, no. 8, pp. 1309-1315, 2013.

[9] S. Fernández-Tomé, S. Ramos, I. Cordero-Herrera, I. Recio, L. Goya, and B. Hernández-Ledesma, "In vitro chemo-protective effect of bioactive peptide lunasin against oxidative stress in human HepG2 cells," Food Research International, vol. 62, pp. 793-800, 2014.

[10] J.-F. Yuan, Z.-Q. Zhang, Z.-C. Fan, and J.-X. Yang, "Antioxidant effects and cytotoxicity of three purified polysaccharides from Ligusticum chuanxiong Hort.," Carbohydrate Polymers, vol. 74, no. 4, pp. 822-827, 2008.

[11] J.-L. Mau, H.-C. Lin, and C.-C. Chen, "Antioxidant properties of several medicinal mushrooms," Journal of Agricultural and Food Chemistry, vol. 50, no. 21, pp. 6072-6077, 2002.

[12] B. Yan, L. Jing, and J. Wang, "A polysaccharide (PNPA) from Pleurotus nebrodensis offers cardiac protection against ischemia-reperfusion injury in rats," Carbohydrate Polymers, vol. 133, pp. 1-7, 2015. 
[13] S. Ananthi, H. R. B. Raghavendran, A. G. Sunil, V. Gayathri, G. Ramakrishnan, and H. R. Vasanthi, "In vitro antioxidant and in vivo anti-inflammatory potential of crude polysaccharide from Turbinaria ornata (Marine Brown Alga)," Food and Chemical Toxicology, vol. 48, no. 1, pp. 187-192, 2010.

[14] I. Sarangi, D. Ghosh, S. K. Bhutia, S. K. Mallick, and T. K. Maiti, "Anti-tumor and immunomodulating effects of Pleurotus ostreatus mycelia-derived proteoglycans," International Immunopharmacology, vol. 6, no. 8, pp. 1287-1297, 2006.

[15] A. Zhang, N. Xiao, P. He, and P. Sun, "Chemical analysis and antioxidant activity in vitro of polysaccharides extracted from Boletus edulis," International Journal of Biological Macromolecules, vol. 49, no. 5, pp. 1092-1095, 2011.

[16] I. Giavasis, "Bioactive fungal polysaccharides as potential functional ingredients in food and nutraceuticals," Current Opinion in Biotechnology, vol. 26, pp. 162-173, 2014.

[17] Y. Mao, J. Mao, and X. Meng, "Extraction optimization and bioactivity of exopolysaccharides from Agaricus bisporus," Carbohydrate Polymers, vol. 92, no. 2, pp. 1602-1607, 2013.

[18] F. R. Smiderle, A. C. Ruthes, J. van Arkel et al., "Polysaccharides from Agaricus bisporus and Agaricus brasiliensis show similarities in their structures and their immunomodulatory effects on human monocytic THP-1 cells," BMC Complementary and Alternative Medicine, vol. 11, article no. 58, 2011.

[19] X. Ding, F. Zhu, and S. Gao, "Purification, antitumour and immunomodulatory activity of water-extractable and alkaliextractable polysaccharides from Solanum nigrum L.," Food Chemistry, vol. 131, no. 2, pp. 677-684, 2012.

[20] S. Miao, X. Mao, R. Pei et al., "Antitumor activity of polysaccharides from Lepista sordida against laryngocarcinoma in vitro and in vivo," International Journal of Biological Macromolecules, vol. 60, pp. 235-240, 2013.

[21] C. Zhang, S. Li, J. Zhang et al., "Antioxidant and hepatoprotective activities of intracellular polysaccharide from Pleurotus eryngii SI-04," International Journal of Biological Macromolecules, vol. 91, pp. 568-577, 2016.

[22] B. Li, X. Zhang, M. Wang, and L. Jiao, "Characterization and antioxidant activities of acidic polysaccharides from Gynostemma pentaphyllum (Thunb.) Markino," Carbohydrate Polymers, vol. 127, pp. 209-214, 2015.

[23] J. Zhang, M. Liu, Y. Yang et al., "Purification, characterization and hepatoprotective activities of mycelia zinc polysaccharides by Pleurotus djamor," Carbohydrate Polymers, vol. 136, Article ID 10377, pp. 588-597, 2016.

[24] N. Smirnoff and Q. J. Cumbes, "Hydroxyl radical scavenging activity of compatible solutes," Phytochemistry, vol. 28, no. 4, pp. 1057-1060, 1989.

[25] K. Shimada, K. Fujikawa, K. Yahara, and T. Nakamura, "Antioxidative properties of xanthan on the autoxidation of soybean oil in cyclodextrin emulsion," Journal of Agricultural and Food Chemistry, vol. 40, no. 6, pp. 945-948, 1992.

[26] T. C. P. Dinis, V. M. C. Madeira, and L. M. Almeida, "Action of phenolic derivatives (acetaminophen, salicylate, and 5aminosalicylate) as inhibitors of membrane lipid peroxidation and as peroxyl radical scavengers," Archives of Biochemistry and Biophysics, vol. 315, no. 1, pp. 161-169, 1994.

[27] D. Gan, L. Ma, C. Jiang, R. Xu, and X. Zeng, "Production, preliminary characterization and antitumor activity in vitro of polysaccharides from the mycelium of Pholiota dinghuensis Bi," Carbohydrate Polymers, vol. 84, no. 3, pp. 997-1003, 2011.
[28] C. Jiang, Q. Xiong, D. Gan et al., "Antioxidant activity and potential hepatoprotective effect of polysaccharides from Cyclina sinensis," Carbohydrate Polymers, vol. 91, no. 1, pp. 262268, 2013.

[29] L. Luo, M. Wu, L. Xu et al., "Comparison of physicochemical characteristics and anticoagulant activities of polysaccharides from three sea cucumbers," Marine Drugs, vol. 11, no. 2, pp. 399417, 2013.

[30] W. Dröge, "Free radicals in the physiological control of cell function," Physiological Reviews, vol. 82, no. 1, pp. 47-95, 2002.

[31] Q. You, X. Yin, S. Zhang, and Z. Jiang, "Extraction, purification, and antioxidant activities of polysaccharides from Tricholoma mongolicum Imai," Carbohydrate Polymers, vol. 99, pp. 1-10, 2014.

[32] H. Osman, R. Nasarudin, and S. L. Lee, "Extracts of cocoa (Theobroma cacao L.) leaves and their antioxidation potential," Food Chemistry, vol. 86, no. 1, pp. 41-46, 2004.

[33] L. Chun-hui, W. Chang-hai, X. Zhi-liang, and W. Yi, "Isolation, chemical characterization and antioxidant activities of two polysaccharides from the gel and the skin of Aloe barbadensis Miller irrigated with sea water," Process Biochemistry, vol. 42, no. 6, pp. 961-970, 2007.

[34] I. Gülçin, Z. Huyut, M. Elmastaş, and H. Y. Aboul-Enein, "Radical scavenging and antioxidant activity of tannic acid," Arabian Journal of Chemistry, vol. 3, no. 1, pp. 43-53, 2010.

[35] H. Chen, Z. Qu, L. Fu, P. Dong, and X. Zhang, "Physicochemical properties and antioxidant capacity of 3 polysaccharides from green tea, oolong tea, and black tea, Journal of Food Science, vol. 74, no. 6, pp. C469-C474, 2009.

[36] H. Zeng, S. Miao, Y. Zhang et al., "Isolation, preliminary structural characterization and hypolipidemic effect of polysaccharide fractions from Fortunella margarita (Lour.) Swingle," Food Hydrocolloids, vol. 52, pp. 126-136, 2016.

[37] D. Cheng and H. Kong, "The effect of lycium barbarum polysaccharide on alcohol-induced oxidative stress in rats," Molecules, vol. 16, no. 3, pp. 2542-2550, 2011.

[38] M. Ming, L. Guanhua, Y. Zhanhai, C. Guang, and Z. Xuan, "Effect of the Lycium barbarum polysaccharides administration on blood lipid metabolism and oxidative stress of mice fed highfat diet in vivo," Food Chemistry, vol. 113, no. 4, pp. 872-877, 2009.

[39] Q. Ding, D. Yang, W. Zhang et al., "Antioxidant and antiaging activities of the polysaccharide TLH-3 from Tricholoma lobayense," International Journal of Biological Macromolecules, vol. 85, pp. 133-140, 2016.

[40] Q. Zhang, N. Li, G. Zhou, X. Lu, Z. Xu, and Z. Li, "In vivo antioxidant activity of polysaccharide fraction from Porphyra haitanesis (Rhodephyta) in aging mice," Pharmacological Research, vol. 48, no. 2, pp. 151-155, 2003.

[41] C. A. Yao, R. Ignell, and J. R. Carlson, "Chemosensory coding by neurons in the coeloconic sensilla of the Drosophila antenna," Journal of Neuroscience, vol. 25, no. 37, pp. 8359-8367, 2005.

[42] N. Xu, Z. Gao, J. J. Zhang et al., "Hepatoprotection of enzymaticextractable mycelia zinc polysaccharides by Pleurotus eryngii var. tuoliensis," Carbohydrate Polymers, vol. 157, pp. 196-206, 2017.

[43] Y. Lu, M. Ye, S. Song, L. Li, F. Shaikh, and J. Li, "Isolation, purification, and anti-aging activity of melanin from Lachnum singerianum," Applied Biochemistry and Biotechnology, vol. 174, no. 2, pp. 762-771, 2014. 
[44] J. T. Rotruck, A. L. Pope, H. E. Ganther, A. B. Swanson, D. G. Hafeman, and W. G. Hoekstra, "Selenium: biochemical role as a component of glatathione peroxidase," Science, vol. 179, no. 4073, pp. 588-590, 1973.

[45] D. Bagchi, M. Bagchi, E. A. Hassoun, and S. J. Stohs, "In vitro and in vivo generation of reactive oxygen species, DNA damage and lactate dehydrogenase leakage by selected pesticides," Toxicology, vol. 104, no. 1-3, pp. 129-140, 1995. 


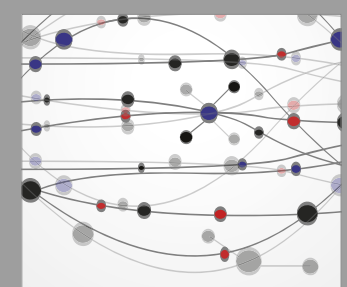

The Scientific World Journal
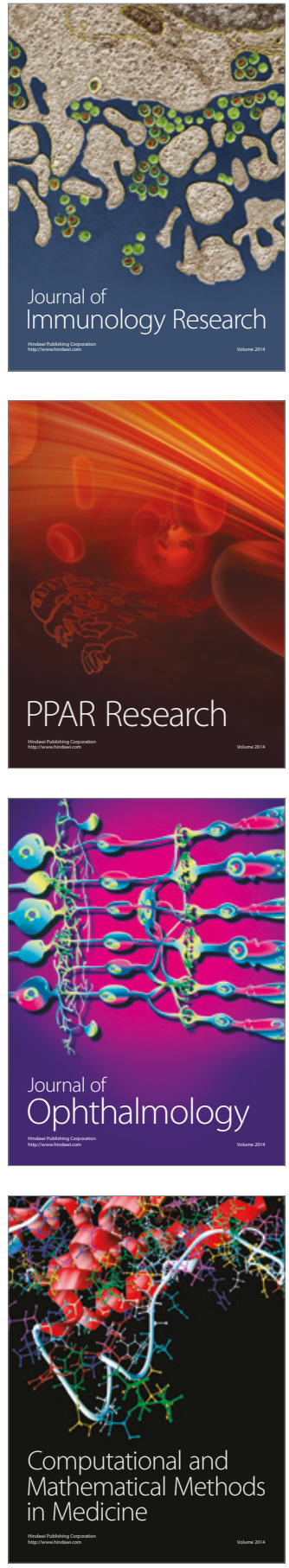

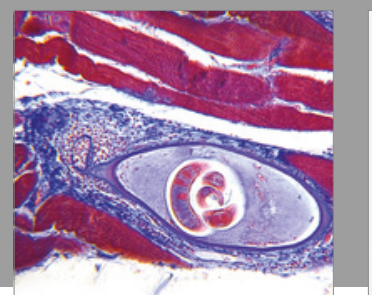

Gastroenterology Research and Practice
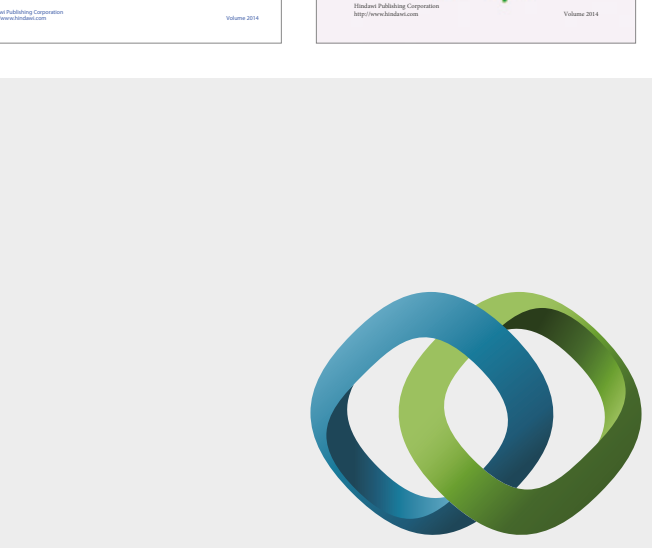

\section{Hindawi}

Submit your manuscripts at

https://www.hindawi.com
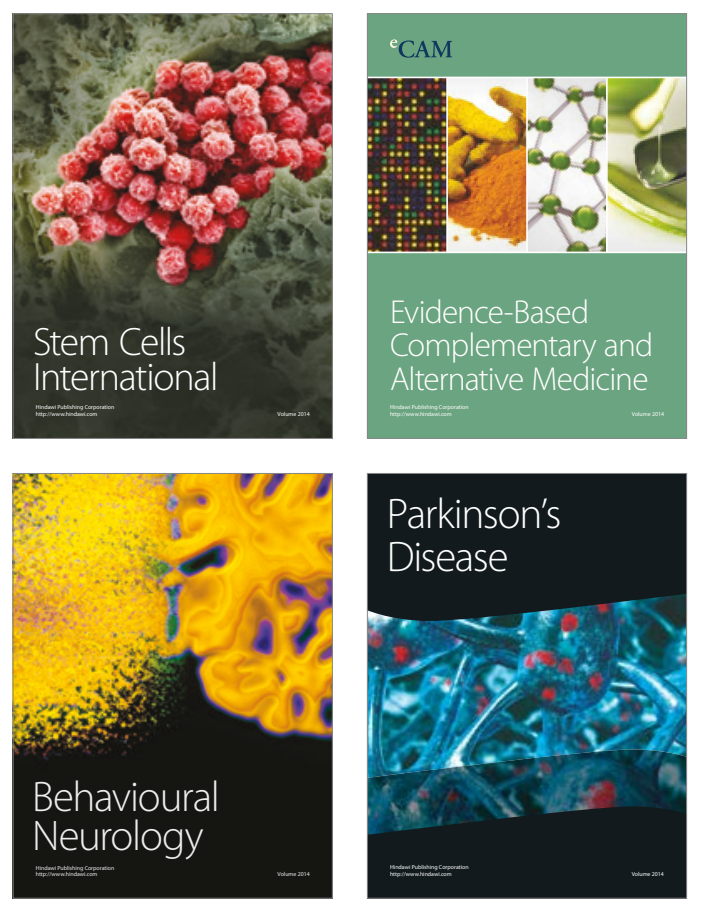
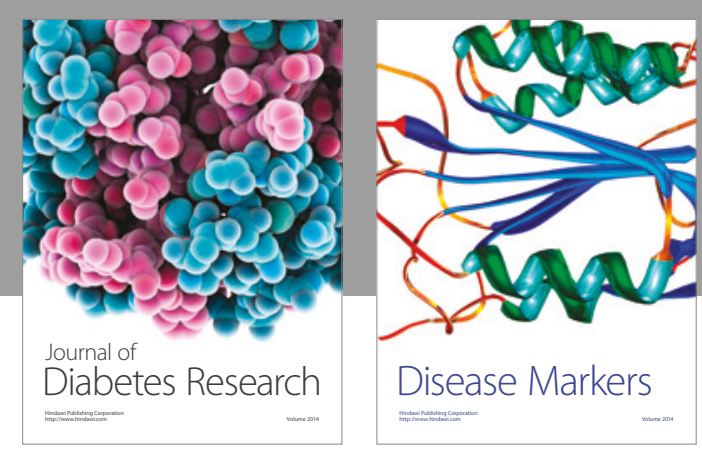

Disease Markers
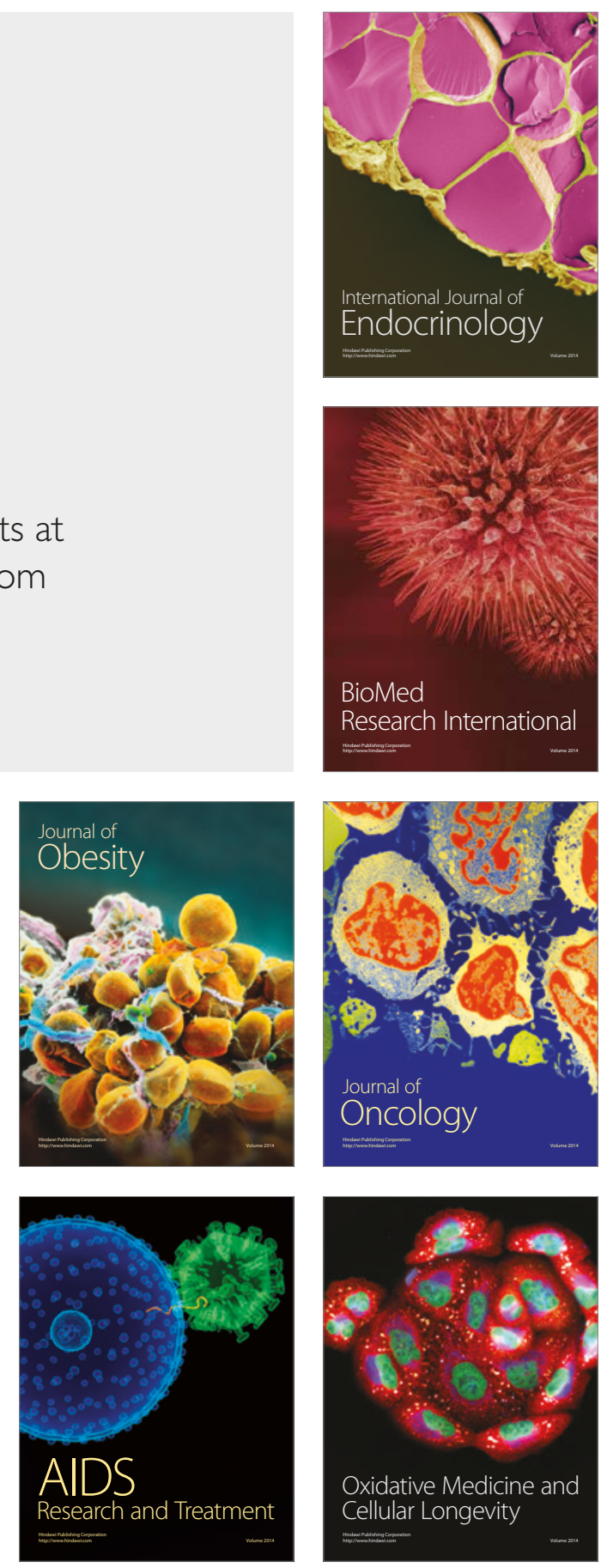